\title{
E.O.R.T.C. Phase II Study of Cisplatin in Cyvadic-Resistant Soft Tissue Sarcoma
}

\author{
VIVIEN H. C. BRAMWELL,* A. BRUGAROLAS,$\uparrow H$. T. MOURIDSEN,+ FRANÇOISE CHEIX,$\S$ \\ R. DE JAGER, $\|$ A. T. VAN OOSTEROM, $\uparrow$ G. P. VENDRIK, ${ }^{*}$ H. M. PINEDO, $\dagger \dagger$ \\ R. SYLVESTER ++ and MARLENE DE PAUW ++ \\ *Cancer Research Campaign, Department of Medical Oncology, Christie Hospital and Holt Radium Institute, Manchester \\ $M 209 B X$, England \\ $\uparrow$ Centre de Oncologie Policlinicas, Hospital General de Asturies, Oviedo, Spain \\ ${ }_{+}$Department R1 I, Finsen Instituten, 40 Strandboulevarden, 2100 Copenhagen, Denmark \\ §Centre Léon Bérard, 28 rue Laënnec, 69 Lyon 8c, France \\ ||Service de Médecine Interne, Institut Jules Bordet, 1 rue Héger-Bordet, 1000 Bruxelles, Belgium \\ -Academisch Ziekenhuis, Department of Radiotherapy and Medical Oncology, 10 Rijnsburgerweg, Leiden, Holland \\ **Academisch Ziekenhuis, 101 Catharijnesingel, Utrecht, Holland \\ $\dagger \dagger$ Academisch Ziekenhuis, der Vrije Universiteit, Amsterdam, De Boelelaan 1117, Amsterdam, Holland \\ ${ }_{++}^{++E . O . R . T . C . ~ D a t a ~ C e n t e r, ~ I n s t i t u t ~ J u l e s ~ B o r d e t, ~} 1$ rue Héger-Bordet, 1000 Bruxelles, Belgium
}

\begin{abstract}
Cis-diamminodichloroplatinum (II) (cis-DDP), $100 \mathrm{mg} / \mathrm{m}^{2}$ every 3 weeks was administered to 24 patients with advanced soft tissue sarcoma. All patients had received extensive prior chemotherapy and had measurable progressive disease and normal renal function on entry to the study. There were no objective responses in the 17 patients receiving an adequate trial of therapy. Nausea and vomiting were universal. Renal impairment was moderate in 2 patients and mild in 4 . Serial audiometry detected hearing loss at high frequencies in 3 patients.
\end{abstract}

\section{INTRODUCTION}

Cis-Diamminodichloroplatinum (II) (cisDDP), an inorganic co-ordination complex of platinum has shown considerable activity in a number of human tumours, notably testicular [1], ovarian [2] and bladder cancers [3]. There is also evidence of activity in osteosarcoma and Ochs [4] has reported 1 complete remission of pulmonary metastases continuing at 18 months and 4 partial remissions in 8 patients, 7 of whom had relapse of disease following adjuvant therapy. Patients were given $20 \mathrm{mg} / \mathrm{m}^{2} /$ day $\times 5$ or $120 \mathrm{mg} / \mathrm{m}^{2}$ as a single dose, with forced osmotic diuresis. Baum [5], giving $3 \mathrm{mg} / \mathrm{kg}$ every 3 weeks to 17 patients who had had prior exposure to high dose methotrexate and adriamycin, obtained one complete remission lasting $8+$ weeks and 2 partial remissions. The only data available on the effect of cis-DDP in soft tissue sarcoma comes from a recently completed South-West Oncology Group study [6], using cis-DDP $15 \mathrm{mg} / \mathrm{m}^{2} \times 5$ every 4 weeks, which produced 3 partial remissions in 42 patients.

Accepted 15 May 1979.
This study by the Sarcoma Group of the European Organisation for Research on Treatment of Cancer (E.O.R.T.C.) has also evaluated cis-DDP in advanced soft tissue sarcoma. Early studies showed a high incidence of renal toxicity $[7,8]$ predicted by animal experiments [9]. Following the experiments of Cuitkovic [10] showing that massive hydration or mannitol infusion could prevent renal toxicity in dogs, Hayes [11] and Merrin [12] have demonstrated the value of similar measures in patients.

\section{MATERIALS AND METHODS}

Patients

Patients with histologically proven soft tissue sarcoma, above the age of $20 \mathrm{yr}$ and with a Karnofsky performance status of at least 50 were considered eligible for this study. Other criteria for admission included the presence of measurable progressive disease, no chemotherapy within the previous 4 weeks and adequate renal (creatinine clearance $>80 \mathrm{ml} / \mathrm{min}$, or serum creatinine $<120 \mu$ mole $/ 1)$ and bone marrow function $(\mathrm{WBC}>3000$, platelets $>125,000)$. 
Pretreatment investigations included clinical evaluation with measurement of lesions, Karnofsky grading, full blood-cell count, urea and electrolytes, liver function tests, chest $\mathrm{X}$ ray, serum creatinine and creatinine clearance. Thesc were repeated after 2 courses of treatment, 6 weeks after commencing therapy. Pre- and post-treatment pure tone audiograms were obtained in the majority of patients.

\section{Drug administration}

Cis-diamminodichloroplatinum II (cisDDP), $100 \mathrm{mg} / \mathrm{m}^{2}$ was dissolved in 1 litre of $5 \%$ dextrose or normal saline containing $37.5 \mathrm{~g}$ mannitol and infused over $3 \mathrm{hr}$. Adequate hydration was ensured by infusing 1 litre of normal saline in the $4 \mathrm{hr}$ preceding drug administration and 3 litre of normal saline in the following $24 \mathrm{hr}$. A second course of trcatment was administered after 3 weeks, the dose being escalated to $120 \mathrm{mg} / \mathrm{m}^{2}$ if no toxicity resulted from the previous course.

Early in the study, cis-DDP was administered in $5 \%$ dextrose, but this was changed to normal saline following a report suggesting that the drug was unstable in $5 \%$ dextrose [13]. However, a recent study by Repta [14] suggests that in the presence of small amounts of chloride ion, little drug inactivation occurs within $3 \mathrm{hr}$.

\section{RESULTS}

Characteristics of the 24 evaluable patients are shown in Table 1 . All had received extensive prior chemotherapy which, with one exception, was a drug combination which included adriamycin. All patients had received radiotherapy to the primary site and in three, lung metastases had also been irradiated. Three patients received 3 courses of cis-DDP, one received 4 , and a further patient received 6 courses.

Seventeen patients received 2 courses of chemotherapy and are evaluable for response. In 8 patients, dose escalation for the sccond course was possible whereas 8 received the same dose and 1 patient had the dose reduced by $50 \%$. The remaining 7 patients received one course of treatment and are evaluable for analysis of toxicity only. The second course was withheld in 3 patients because of rapidly progressive disease and, in 3, because of toxicity. One patient refused further treatment.

There were no remissions, 13 patients had progressive disease and 4 had stabilisation of discase or less than $50 \%$ reduction of measurable discase.
Table 1. Characteristics of evaluable patients

\begin{tabular}{|c|c|c|}
\hline \multicolumn{2}{|l|}{$\begin{array}{c}\text { Total Vo. } \\
\text { Male } \\
\text { Female }\end{array}$} & $\begin{array}{l}24 \\
13 \\
11\end{array}$ \\
\hline Age $(y r)$ & $\begin{array}{l}\text { (range) } \\
\text { (mcan) }\end{array}$ & $\begin{array}{c}2372 \\
46.5\end{array}$ \\
\hline
\end{tabular}

Sarcoma type
Rhabdomyosarcoma
Fibrosarcoma
Synovial sarcoma
leiomyosarcoma
Lindiffercntiated
Malignant fibrous histiocytoma
*Other

\begin{tabular}{lr} 
Site of disease & \\
Local recurrence/residual & 12 \\
Distant motastases & \\
Pulmonary & 18 \\
Lymph nodes & 3 \\
Bone & 2 \\
Liver & 1 \\
Skin & 1 \\
\hline
\end{tabular}

* Neurofibrosarcoma, liposarcoma, angiosarcoma.

\section{Toxicily}

Nausea and vomiting were moderate in 17 patients, mild in 6 , one patient refusing further treatment. Irreversible renal toxicity occurred in one patient, serum creatinine rising from 102 to $245 / \mu$ mole $/ 1,3$ wecks later and remaining elevated at $258 \mu$ mole $/ 1$ four days before death, which occurred from progressive malignant disease, 7 weeks after treatment. Autopsy showed a mild left hydronephrosis and hydro-ureter (which had been noted on an IVP prior to treatment) but the kidneys were histologically normal. One patient was taken off study when the creatinine clearance fell from 80 to $67 \mathrm{ml} / \mathrm{min}$ after the first course of treatment. Mild reversible elevation of serum creatinine occurred in 4 patients. The remaining 18 patients had no evidence of renal impairment. Serial audiograms were performed in 18 patients. Fifteen showed no change in hearing, but 3 showed significant hearing loss at high frequencies $(>4000 \mathrm{~Hz})$. There was no symptomatic impairment of hearing. Mild leucopaenia (WBC, 2000-3000 at 3 weeks) occurred in 5 patients and moderate leucopacnia (WBC, 1500 at 3 weeks) in one patient. Moderate thrombocytopacnia (platelets $<50,000$ at 3 wecks) occurred in one patient. There was no other toxicity.

\section{DISCUSSION}

As there were no major therapeutic responses in 17 patients receiving an adequate 
trial of cis-DDP, it is unlikely that this drug has significant activity in soft tissue sarcoma, despite the fact that all patients had received extensive prior chemotherapy. This concurs with the findings of the South-West Oncology Group [6]. These results are particularly disappointing in view of the promising results in osteosarcoma $[4,5]$, although the majority of therapeutic responses in this tumour have been observed in children (age $<20 \mathrm{yr}$ ), and experience in adults is not so favourable [6].

Nausea and vomiting were almost universal, although ameliorated in some cases by premedication with diazepam and metochlo- pramide. Adequate hydration and mannitol infusion seems to have prevented major renal toxicity. The only patient who developed irreversible renal impairment had a pre-existing abnormality of the urinary tract, which has been suggested by Hayes et al. [11] to predispose to renal toxicity of cis-DDP. Despite heavy prior chemotherapy, bone marrow depression (mainly leucopaenia) following cisDDP was mild and rapidly reversible. Ototoxicity, only evident on serial audiometry, was present in 3/18 patients; a lower incidence than has been reported in earlier studies $[11,15]$.

\section{REFERENCES}

1. L. H. Einhorn and J. Donahue, Cis-diammine-dichloroplatinum, vinblastine and bleomycin combination chemotherapy in disseminated testicular cancer. Ann. intern. Med. 87, 293 (1977).

2. E. Wiltshaw and T. Kroner, Phase II study of cisdichlorodiammineplatinum (II) (NSC-119875) in advanced adenocarcinoma of the ovary. Cancer Treat. Rep. 60, 55 (1976).

3. A. Yagoda, R. C. Watson, J. C. Gonzalez-Vitale, H. Grabstald and W. F. Whitmore, Cis-dichlorodiammineplatinum (II) in advanced bladder cancer. Cancer Treat. Rep. 60, 917 (1976).

4. J. J. Ochs, A. I. Freeman, H. O. Douglass, Jr., D. S. Higby, E. R. Mindell and L. F. SINks, Cis-dichlorodiammineplatinum (II) in advanced osteogenic sarcoma. Cancer Treat. Rep. 62, 237 (1978).

5. E. Baum, P. Gaynon, L. Greenberg, W. Krivit and D. Hammond, Cisplatinum diammine dichloride-phase II study in osteogenic sarcoma of childhood. Cancer Treat Rep. (In press).

6. R. Stevens, C. Coltman, A. Rossof, M. S.umon, F. Panettiere, M. AlSarraf and J. Bonnet, South West Oncology Group studies with cis-platinum in adult patients. Cancer Treat Rep. (In press).

7. D. J. Higby, H. J. Wallace and J. F. Holland, Cisdiamminedichloroplatinum (NSC-119875): a phase I study. Cancer Chemother. Rep. 57, 459 (1973).

8. J. S. Kovach, C. G. Moertel, A. J. Schutt, R. G. Reitemeier and R. G. HaHn, Phase II study of cis-diamminedichloroplatinum (NSC-119875) in advanced carcinoma of the large bowel. Cancer Chemother. 57, 357 (1973).

9. U. Schaeppi, I. A. Heyman, R. W. Fleischman, H. Rosenkrantz, V. Illevski, R. Phelan, D. A. Cooney and R. D. Davis, Cisdichlorodiammineplatinum (II) (NSC-119875). Preclinical toxicologic evaluation of intravenous injection in dogs, monkeys and mice. Toxicol. appl. Pharmacol. 25, 230 (1973).

10. E. Guitkovic, J. Spaulding, V. Bethune, J. Martin and W. F. Whitemore, Improvement of cis-dichlorodiammineplatinum (NSC-119875): therapeutic index in an animal model. Cancer (Philad.) 39, 1357 (1977).

11. D. M. Hayes, E. Guitkovic, R. B. Golbey, E. Scheiner, L. Helson and I. H. Krakoff, High-dose cis-platinum-diammine-dichloride: amelioration of renal toxicity by mannitol diuresis. Cancer (Philad.) 39, 1372 (1977).

12. C. MErrin, A new method to prevent toxicity with high doses of cis-diammine platinum (therapeutic efficacy in previously treated widespread and recurrent testicular tumors). Proc. Amer. Soc. clin. Oncol. 17, 243 (1976).

13. R. H. EARHart, Instability of cis-dichlorodiammineplatinum in dextrose solution. Cancer Treat. Rep. 62, 1105 (1978).

14. A. J. Repta, D. F. Long and A. A. Hincol, Cis-diaminodichloroplatinum (II)-stability in aqueous vehicles. Cancer Treat. Rep. 63, 229 (1979).

15. I. J. Piel; D. Meyer, C. P. Perlia and Y. I. Wolfe, Effects of cisdiaminodichloroplatinum (NSC-119875) on hearing function in man. Cancer Chemother. Rep. 58, 871 (1974). 